\title{
Análise do Efeito Higrotérmico no Comportamento em Fadiga de Compósitos de PPS/Fibras de Carbono
}

\author{
Maria C. M. de Faria, Maria O. H. Cioffi, Edson C. Botelho \\ Departamento de Materiais e Tecnologia, UNESP
}

\begin{abstract}
Resumo: O contínuo crescimento na utilização de compósitos termoplásticos em componentes estruturais na indústria aeroespacial devese, primordialmente, à flexibilidade de projeto, excelência de suas propriedades mecânicas e baixa massa específica, aliadas aos elevados valores de resistência mecânica e rigidez e baixa incidência de corrosão, atendendo aos severos requisitos de desempenho quando em serviço dessas estruturas. Componentes com exigências estruturais, quando expostos a ambientes agressivos como elevada temperatura e umidade, podem ter suas propriedades mecânicas sensibilizadas por esses fatores ambientais, e devem ser cuidadosamente avaliados antes de serem colocados em serviço. Em função do que foi exposto este trabalho tem como objetivo contribuir para a avaliação do efeito higrotérmico na resistência à fadiga do compósito termoplástico PPS/fibras de carbono. Os materiais estudados foram cedidos pela empresa holandesa TenCate, fornecedora de laminados da Airbus e EMBRAER. Os resultados obtidos neste trabalho mostram que compósitos de PPS/fibras de carbono apresentam um aumento nos valores de resistência à tração quando condicionados higrotermicamente, devido à plasticização desta matriz polimérica, aumentando, consecutivamente, sua tenacidade à fratura. Entretanto, a partir dos ensaios realizados, foi constatado que o condicionamento higrotérmico não alterou de forma significativa o comportamento de vida em fadiga dos laminados PPS-C.
\end{abstract}

Palavras-chave: PPS, compósitos termoplásticos, propriedades mecânicas, fadiga.

\section{On the Analysis of Hygrothermal Effect on Fatigue Behavior of PPS/Carbon Fiber Composite}

Abstract: The continued growth in the use of polymer composites in structural components in the aerospace industry is due primarily to the design flexibility, excellent mechanical properties and low density, combined with the high values of mechanical strength and stiffness and low incidence of corrosion, with which these structures meet several performance requirements when in service. Components with structural requirements may have their mechanical properties affected when exposed to harsh environments such as high temperature and humidity, and should be carefully evaluated before being put into service. The aim of the present work is to evaluate the hygrothermal effect on the fatigue resistance of thermoplastic PPS/carbon fiber composite. These laminates were obtained from TenCate Company, which provides composite laminates to Airbus and Embraer. PPS/carbon fibers composites exhibited increased tensile strength under hygrothermal conditioning due to plasticization of the polymer matrix, with the fracture toughness being also increased. In contrast, the hygrothermal conditioning did not alter significantly the behavior of fatigue life of laminates from PPS/carbon fiber composite.

Keywords: PPS, thermoplastic composites, mechanical properties, fatigue.

\section{Introdução}

Atualmente o uso de materiais compósitos termoplásticos em substituição aos materiais metálicos tradicionalmente empregados na indústria aeroespacial tem crescido consideravelmente, devido à constante evolução tecnológica apresentada por essa classe de materiais. Quando comparados aos compósitos termorrígidos, os compósitos termoplásticos vêm conquistando a cada ano uma maior participação de mercado devido a excelência de suas propriedades mecânicas tais como alta resistência mecânica, elevada rigidez, baixa massa específica, maior tenacidade à fratura, maior resistência ao impacto, à vida em fadiga, associadas à versatilidade de produção em série, capacidade de serem armazenados por mais tempo antes do uso e grande potencial de reciclagem ${ }^{[1-4]}$. No setor aeronáutico, a utilização de compósitos termoplásticos é promissora na construção de fuselagens, possibilitando, com isso, uma redução de peso de aproximadamente $25 \%$ em relação às estruturas metálicas fabricadas com ligas de alumínio 2024-T3. Geralmente, os compósitos termoplásticos reforçados com fibras contínuas utilizam uma elevada fração volumétrica de reforço (>50\%), buscando atingir os requisitos de alto desempenho mecânico exigidos em serviço. Além dos fatores já citados anteriormente, o entusiasmo pelo uso de termoplásticos é devido a diferentes razões das quais se destacam: processabilidade, reparos de danos, capacidade de reprocessamento, resistência ao fogo, maior temperatura de serviço, e baixa absorção de umidade ${ }^{[5]}$.

Matrizes termoplásticas de alto desempenho tais como o PPS (poli sulfeto de fenileno), PEI (poli éter imida), PEEK (poli éter éter cetona) e PEKK (poli éter cetona cetona) estão sendo utilizadas como matérias-primas precursoras de compósitos avançados, principalmente os reforçados com fibras de carbono, permitindo uma significativa redução no peso final do componente, além de contribuir para a melhoria das resistências à corrosão e à fadiga de uma infinidade de estruturas que vem sendo utilizadas em aeronaves de última geração, plataformas marítimas de petróleo, satélites, submarinos, foguetes, veículos automotores, trens de alta velocidade, artigos esportivos e implantes ortopédicos, entre outras aplicações ${ }^{[5]}$.

$\mathrm{O}$ poli (sulfeto de fenileno) consiste em uma matriz termoplástica, semicristalina, composta por uma série de anéis aromáticos alternados com átomos de enxofre e com elevadas temperaturas de transição vítrea $\left(90^{\circ} \mathrm{C}\right)$ e de fusão $\left(280^{\circ} \mathrm{C}\right)$, quando comparada a outras matrizes termoplásticas convencionalmente utilizadas $^{[6,7]}$. Esta matriz polimérica é proveniente da polimerização por condensação do para-dicloro-benzeno com o sulfeto de sódio, em solventes polares. Este material apresenta 
um custo elevado, porém, a estabilidade da estrutura molecular lhe confere características especiais, tais como excelente resistência química e baixa degradação térmica. Em relação ao desempenho mecânico da matriz PPS destacam-se: elevado módulo de flexão; elevados valores de resistências à fluência e à tração e elevada resiliência. Esta matriz polimérica também apresenta baixa absorção de umidade (de 0,01 a $0,05 \%$ ) quando comparada a outras matrizes atualmente utilizadas no setor aeroespacial ${ }^{[7-10]}$.

À medida que o desenvolvimento tecnológico foi incorporando novos componentes e equipamentos, como nas indústrias automobilística e aeroespacial, submetidos continuamente a esforços dinâmicos e vibrações, o fenômeno de fadiga passou a representar a causa de mais de $90 \%$ das falhas em serviço. A falha por fadiga é particularmente imprevisível, pois acontece sem que haja qualquer aviso prévio, sendo de natureza frágil, mesmo em materiais dúcteis, no sentido de que existe pouca, quando alguma deformação plástica generalizada associada com a falha ${ }^{[11]}$. O processo ocorre pela iniciação e propagação de trincas e, em geral, a superfície de fratura é perpendicular a uma direção de tensão de tração aplicada. Estruturas de compósitos em serviço são geralmente submetidas a cargas de fadiga. Danos por fadiga causam uma redução gradual nas propriedades mecânicas dos compósitos, tais como resistência e dureza. A fadiga em compósitos reforçados com fibras contínuas consiste em um fenômeno muito complexo, principalmente quando associada a fatores ambientais (umidade, temperatura, radiação UV, etc). Devido à degradação das propriedades durante o carregamento cíclico, as tensões são continuamente redistribuídas na estrutura do compósito, portanto, o comportamento em fadiga para este material ocorre de forma diferente quando comparados aos materiais metálicos ${ }^{[12-16]}$. Atualmente, várias investigações vêm sendo relatadas com o intuito de se prever o comportamento e a vida em fadiga de laminados termoplásticos. $\mathrm{O}$ dano em fadiga resulta em uma mudança de resistência, rigidez e outras propriedades mecânicas para este tipo de laminado, onde os fenômenos de danos sob várias cargas são significativamente diferentes; por exemplo, formação de trinca devido à ruptura da fibra e a propagação da trinca da matriz a uma elevada carga de tração, resulta em uma falha catastrófica $^{[17-20]}$.

As aeronaves também operam em uma grande variação de condições ambientais tais como ar frio e seco, climas quentes e úmidos, elevada ou baixa taxa de radiação UV, etc; efeitos que dependendo do tempo de exposição podem causar a degradação das propriedades mecânicas, principalmente sua vida em fadiga ${ }^{[21]}$. As propriedades mecânicas dos compósitos de matriz polimérica podem ser degradadas por uma série de efeitos físicos e químicos, portanto é de suma importância entender tanto o material quanto o ambiente operacional a que este se encontra exposto ${ }^{[22,23]}$. Efeitos ambientais como umidade, temperatura, radiação UV, entre outros, presentes na atmosfera devem ser sempre considerados nos projetos de laminados estruturais antes de empregá-los em estruturas aeroespaciais ${ }^{[24-26]}$. A umidade, por exemplo, penetra na matriz polimérica pelo processo de difusão até que a concentração de equilíbrio seja atingida, sendo esse mecanismo acentuado pelo aumento da temperatura. Neste caso, a umidade pode causar a expansão volumétrica da matriz polimérica, gerando pequenas variações dimensionais e tensões internas. A taxa de absorção de umidade no compósito pode ser aumentada por picos térmicos acima de $140{ }^{\circ} \mathrm{C}$, durante pequenos intervalos de tempo (típicos em voos supersônicos), que favorecem o surgimento de danos na forma de trincas superficiais no laminado, microtrincas na matriz e/ou na interface fibra/resina ${ }^{[22-30]}$

Em função do que foi exposto este trabalho tem como objetivo contribuir para a avaliação do efeito higrotérmico na resistência à fadiga de compósitos termoplásticos PPS/fibras de carbono.

\section{Experimental}

Material

\section{Caracterização morfológica}

O compósito de PPS/fibras de carbono utilizado neste trabalho foi fornecido pela empresa holandesa TenCate Advanced Composites. As especificações do material encontram-se apresentadas na Tabela 1. A excelente qualidade que se exige dos laminados estruturais aeronáuticos é assegurada pela quantidade de porosidade, bolsas de resinas, pela presença mínima de vazios, trincas e delaminações que podem ser geradas durante o seu processamento. Desta forma, antes do condicionamento higrotérmico e dos ensaios mecânicos, os laminados em estudo foram caracterizados como recebidos por microscopia óptica. A caracterização microscópica foi realizada utilizando-se um microscópio óptico NIKON, modelo Epiphote 200. A avaliação morfológica também foi realizada nos laminados após serem submetidos aos ensaios mecânicos.

\section{Condicionamento higrotérmico}

O condicionamento higrotérmico em câmara climática é um teste gravimétrico, baseado na norma ASTM 562-85 que controla a alteração do ganho de umidade no compósito em função do tempo, pela medida da mudança de massa em amostras de acompanhamento (controle) completamente expostas à condição de testes, até que essas alcancem o estado efetivo de equilíbrio de umidade na estrutura do laminado (saturação). Para avaliar o efeito do condicionamento ambiental nos compósitos poliméricos estudados, cinco amostras de acompanhamento, e amostras destinadas aos ensaios de tração e fadiga (corpos-deprova), foram submetidas a esse condicionamento. As amostras de acompanhamento e os corpos-de-prova foram expostos à temperatura de $80{ }^{\circ} \mathrm{C}$, onde o teor de umidade relativo selecionado foi de $90 \%$ por um período de oito semanas (tempo para se atingir a saturação de umidade). Estes parâmetros foram programados em uma câmara de condicionamento higrotérmico Marconi modelo MA 835/UR. Antes de iniciar a climatização, todos os corpos-deprova (cdps) e as amostras de controle foram secos em uma estufa a vácuo da marca Quimis modelo Q819V2, por um período médio de 48 horas na temperatura de $60{ }^{\circ} \mathrm{C}$. Após esta etapa de secagem as amostras de acompanhamento foram rapidamente removidas da estufa e pesadas em uma balança analítica Mettler Toledo, enquanto que os corpos-de-prova a serem disponibilizados para os ensaios mecânicos permaneceram na estufa. Em seguida, as amostras de acompanhamento e os corpos-de-prova foram transferidos para a câmara de climatização e iniciado o condicionamento ambiental. A cada semana todas as amostras de acompanhamento eram removidas da câmara e pesadas para acompanhar o ganho de massa, até que a saturação fosse atingida. A partir dos dados de ganho de massa obtidos, foi possível construir um gráfico de ganho de massa médio em função do número de dias em que as amostras de acompanhamento e os cdps permaneceram dentro da câmara climática.

Tabela 1. Características do laminado utilizado neste trabalho.

\begin{tabular}{cc}
\hline Laminado & PPS/Carbono \\
\hline Código & PPS-C \\
Espessura nominal $(\mathrm{mm})$ & 1,86 \\
Tipo de tecido & $5 \mathrm{HS}$ \\
Construção & {$[(0 / 90)]_{3 \text { segundos }}$} \\
Dimensões $(\mathrm{mm})$ & $480 \times 480$ \\
\hline
\end{tabular}




\section{Ensaios de tração}

Os ensaios de tração longitudinal foram realizados em compósitos estudados nas condições ambiente e climatizada em câmara de condicionamento higrotérmico baseados na norma ASTM D3039/D3039 M-00, sendo utilizados corpos-de-prova com dimensões de $120 \mathrm{~mm}$ de comprimento, $25 \mathrm{~mm}$ de largura e $1,86 \mathrm{~mm}$ de espessura. Os ensaios de tração foram realizados em um equipamento INSTRON, modelo $8801 \mathrm{com}$ célula de carga de $10 \mathrm{KN}$, à temperatura ambiente e velocidade de $2 \mathrm{~mm} / \mathrm{min}$.

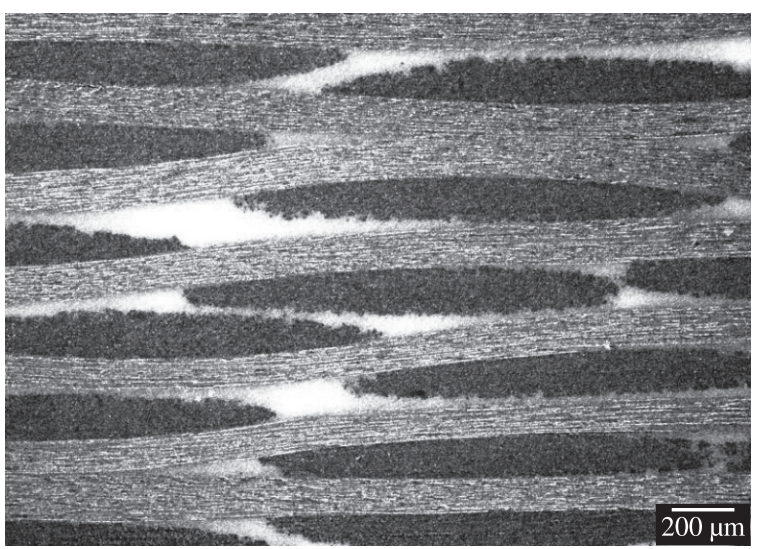

Figura 1. Imagens obtidas por microscopia óptica do laminado estudado: PPS-C.

\section{Ensaios de fadiga}

As amostras dos compósitos poliméricos estudadas nas condições ambiente e climatizada em câmara de condicionamento higrotérmico foram submetidas a ensaios de fadiga do tipo traçãotração. A carga inicial para a execução desse ensaio foi baseada na resistência à tração do compósito utilizando cargas a partir de $75 \%$ da carga de ruptura. Cada ensaio foi realizado aplicando-se uma carga máxima diferente que forneceu um determinado número de ciclos. Para a realização dos ensaios de fadiga foram utilizados 14 corpos-de-prova na condição seco ambiente e 12 corpos-de-prova para os ensaios com o material climatizado. Este método de ensaio foi realizado à temperatura ambiente, utilizando uma frequência de $10 \mathrm{~Hz}$ e razão entre as tensões máximas e mínimas (R) de $0,1 \mathrm{em}$ um equipamento de ensaios universal INSTRON, modelo 8801. O procedimento deste ensaio foi baseado na norma ASTM D3479-96 e a geometria dos corpos-de-prova foi a mesma utilizada nos ensaios de tração.

\section{Resultados e Discussão}

\section{Análise morfológica}

A partir da análise microestrutural pode-se observar que as camadas do compósito termoplástico PPS/fibras de carbono apresentam-se bem compactadas, gerando materiais mais homogêneos e com uma menor quantidade de regiões ricas em matriz entre as camadas de tecido, com boa infiltração da matriz

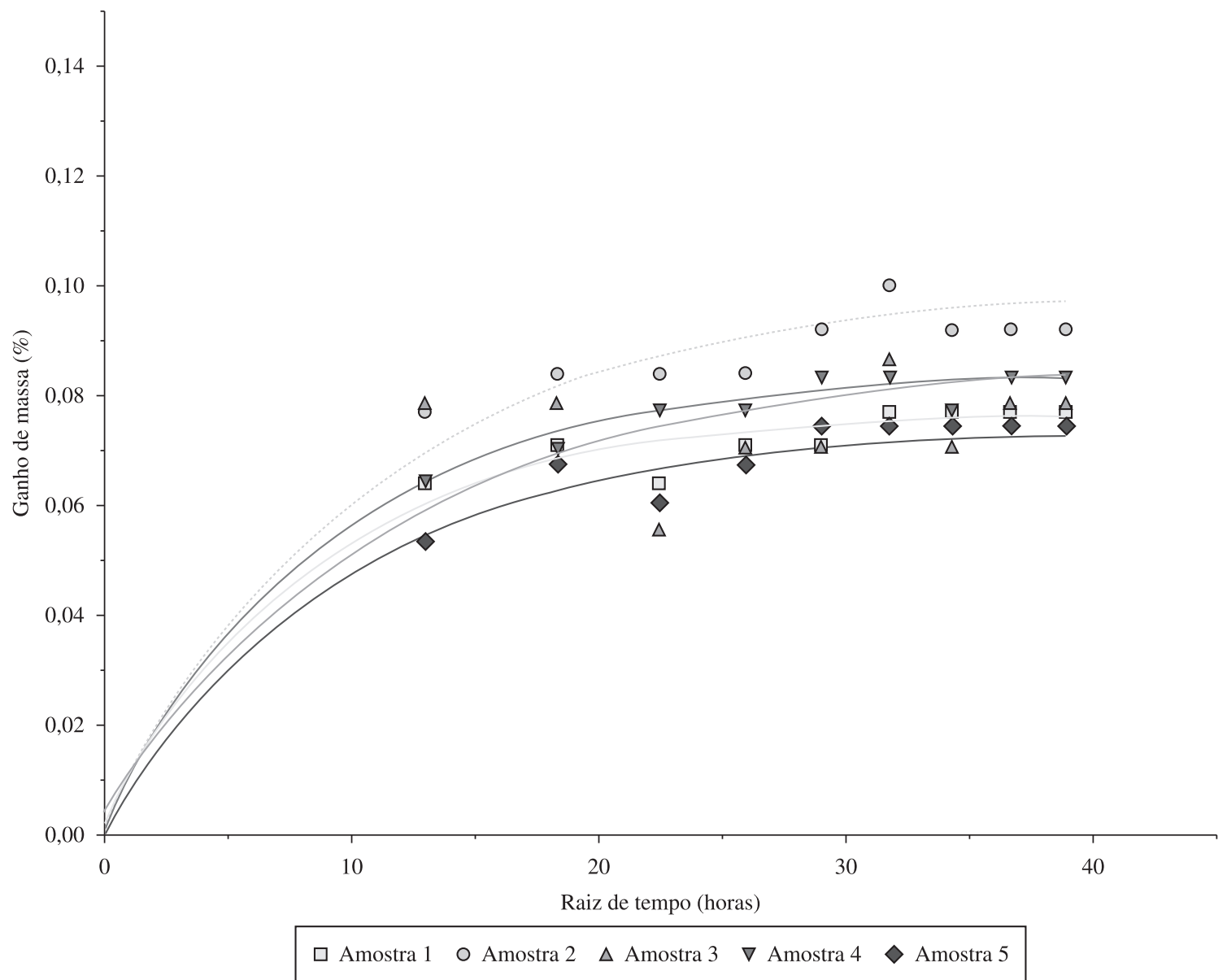

Figura 2. Resultados de ganho de massa (\%). 
polimérica no reforço e uma adequada interface entre a matriz e o reforço (Figura 1). Estas características são desejadas, pois estão diretamente relacionadas com melhores propriedades mecânicas e físicas dos materiais processados. As fotomicrografias obtidas confirmam que o processo de moldagem utilizado produziu um compósito adequado, apresentando poucos vazios ou defeitos intrínsecos ao processo de fabricação que poderiam interferir nos resultados obtidos a partir dos ensaios mecânicos.

\section{Condicionamento ambiental}

A Figura 2 apresenta os valores de ganho de massa do laminado estudado em função do tempo de exposição em câmara climática. $\mathrm{O}$ cálculo da absorção de umidade no compósito exposto à climatização é definido como o ganho médio de massa expresso pela Equação 1, conforme descrito na norma ASTM D5229/D5229-04.

$$
\% \text { umidade }=\frac{\left(\begin{array}{l}
\text { massa da amostra úmida }- \\
- \text { massa da amostra seca }
\end{array}\right)}{\text { massa da amostra seca }} \times 100(\%)
$$

A análise dos dados apresentados na Figura 2 indica que a concentração de umidade nas amostras de controle do laminado de PPS/fibra de carbono aumenta linearmente com o tempo na primeira semana de exposição. Nesta etapa, as amostras absorvem água muito rapidamente, alcançando um estado conhecido como pseudo-equilíbrio, mantendo a quantidade de água praticamente a mesma depois de um determinado período de tempo, sugerindo, a princípio, um comportamento Fickiano. A água permanece no compósito como água livre e tende, com o tempo, a penetrar na matriz polimérica pelo gradiente de concentração. Com a contínua exposição, o processo de absorção de umidade se torna mais lento, e muitos autores atribuem a esse período, o início do processo de relaxação da cadeia polimérica e o preenchimento higrotérmico dos vazios existentes.

Quando comparados com matrizes termorrígidas tais como a matriz epóxi, pode ser constatado que mesmo utilizando elevados valores de temperatura e umidade, os laminados de PPS absorvem um baixo conteúdo de umidade. Este comportamento ocorre devido a diferenças entre a polaridade de matrizes epoxídicas e o PPS; pois quanto maior for a polaridade da matriz polimérica, maior será a sua capacidade de absorção de água. Matriz de PPS apresenta um caráter menos polar, levando consequentemente a uma menor absorção de umidade.

\section{Ensaios de tração}

Os ensaios de resistência à tração foram realizados com o objetivo de caracterizar a influência do efeito higrotérmico sobre as propriedades mecânicas e avaliar as cargas mais adequadas a serem utilizadas para a realização dos ensaios de resistência à fadiga dos compósitos de PPS-C. A Figura 3 apresenta curvas características de tensão $\times$ deformação obtidas dos laminados de PPS-C, climatizados e não climatizados. Como pode ser evidenciado, as amostras climatizadas e não-climatizadas apresentam um comportamento similar, sendo observada uma fratura de natureza frágil em todos os casos analisados. A Tabela 2 apresenta de forma resumida os principais resultados obtidos de resistência à tração para os laminados de PPS-C.

A partir dos resultados apresentados na Figura 3 e na Tabela 2, pode ser constatado que o efeito higrotérmico aumentou a resistência à tração em $12 \%$ para os laminados PPS-C. Desta forma, fica evidente que a saturação de umidade foi favorável aos laminados obtidos com a matriz de PPS. Neste caso, as moléculas de água podem ter formado um maior número de ligações tipo pontes de

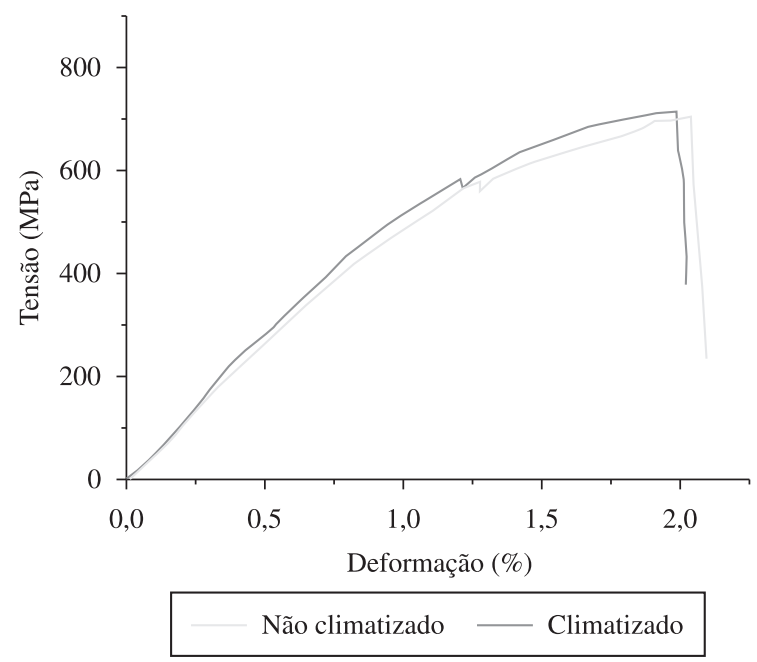

Figura 3. Curvas representativas do ensaio de tração.

Tabela 2. Resultados dos ensaios de resistência à tração.

\begin{tabular}{ccccc}
\hline Laminados & Condição & $\begin{array}{c}\text { Máximo } \\
(\mathbf{M P a})\end{array}$ & $\begin{array}{c}\text { Mínimo } \\
(\mathbf{M P a})\end{array}$ & $\begin{array}{c}\text { Média } \\
(\mathbf{M P a})\end{array}$ \\
\hline PPS-C & $\begin{array}{c}\text { Sem } \\
\text { climatização }\end{array}$ & 826,8 & 740,9 & $791,8 \pm 45,0$ \\
& $\begin{array}{c}\text { Climatização } \\
\text { em câmara }\end{array}$ & 860,5 & 767,9 & $821,8 \pm 48,1$ \\
\hline
\end{tabular}

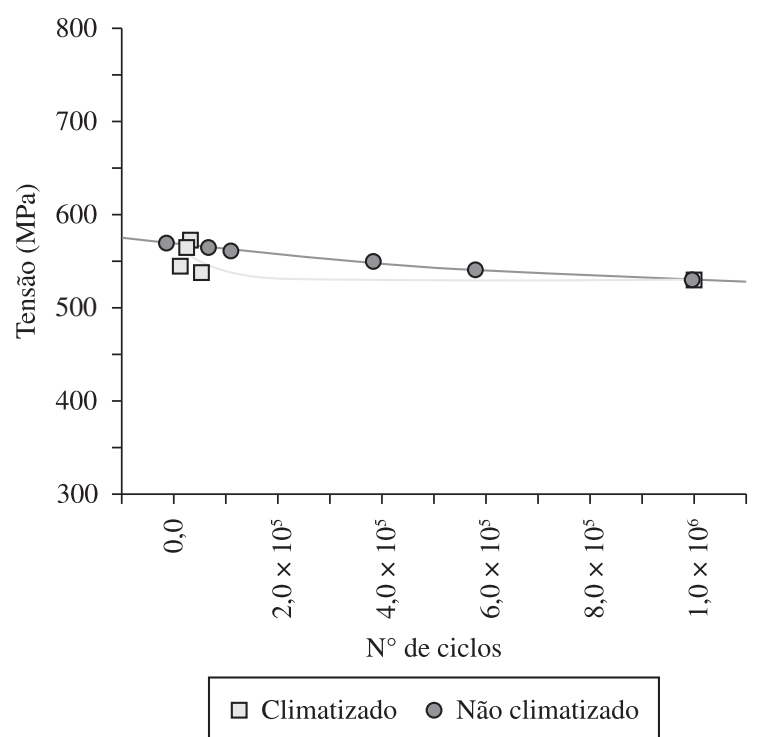

Figura 4. Comportamento em fadiga dos laminados climatizados.

hidrogênio e de van der Waals e, com uma menor possibilidade de ocorrência, até mesmo ligações de natureza covalente. A incorporação das moléculas de água no compósito pode diminuir a rigidez da matriz, aumentando, consequentemente, a sua tenacidade. Este comportamento pode ter sido provocado, principalmente, pela expansão do volume da matriz polimérica e pela ocorrência de um maior distanciamento das cadeias moleculares. Desta forma, a água assume a função de um agente tenacificante, modificando algumas das propriedades mecânicas do compósito e melhorando a transferência de tensões dentro e fora do plano do laminado. 


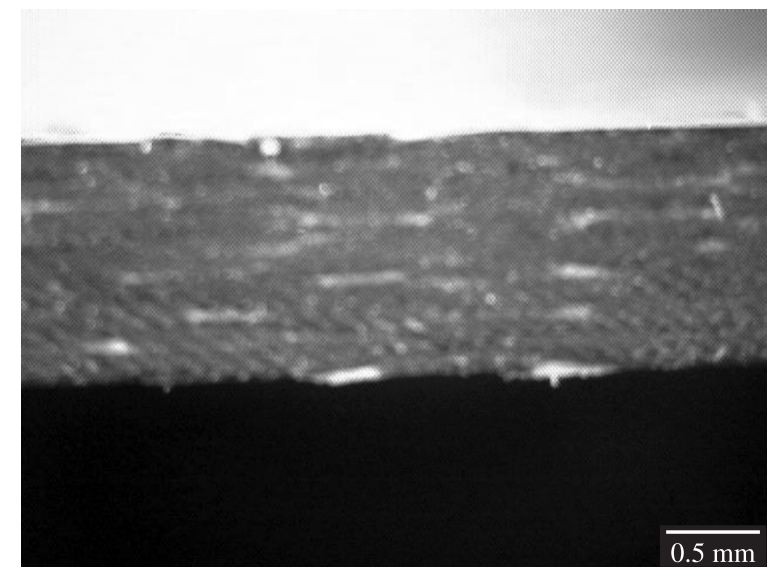

Figura 5. Estereofotomicrografia do laminado PPS-C após ser submetido ao ensaio de fadiga em alto ciclo.

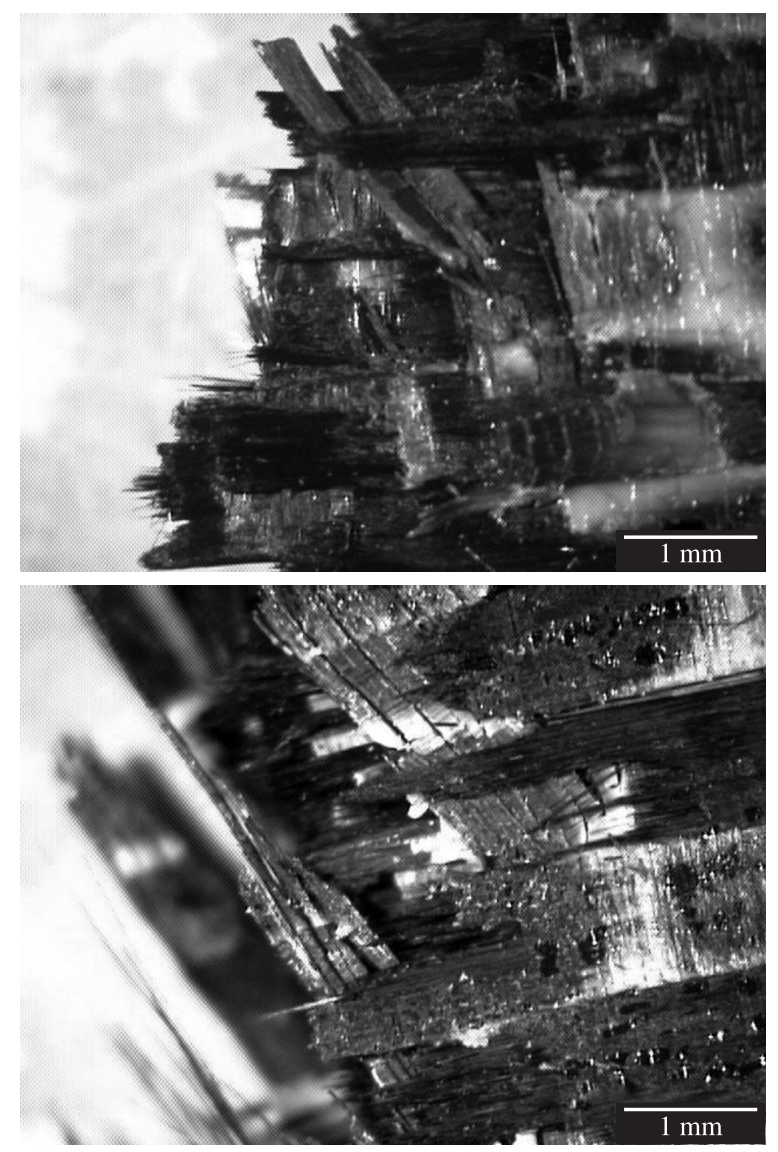

Figura 6. Estereofotomicrografias dos laminados de PPS-C após serem submetidos ao ensaio de fadiga em baixo ciclo: a) não condicionado; e b) condicionado.

\section{Limite de resistência à fadiga}

Para uma estrutura constituída de compósitos poliméricos o comportamento em fadiga é uma consideração relevante em aplicações de engenharia, especialmente na indústria aeroespacial. O estudo do comportamento em fadiga é de suma importância, pois é a maior causa individual de falhas em materiais sob carregamento constante. A avaliação dos efeitos ambientais no comportamento de vida em fadiga nos compósitos para estruturas aeroespaciais é tão importante quanto os efeitos nas propriedades estáticas. A partir dos resultados obtidos de resistência à tração dos laminados de PPS-C, foram levantadas curvas S-N. A Figura 4 apresenta o comportamento de vida em fadiga de dois laminados reforçados com fibras de carbono, nas condições climatizada e não climatizada. Pode ser observado que o condicionamento higrotérmico não alterou de forma significativa a vida em fadiga dos laminados PPS-C, apenas decréscimos de valores de até $4 \%$ da tensão de resistência à ruptura, quando analisado ciclo por ciclo. Estes decréscimos foram mais pronunciados em ensaios realizados a baixos ciclos. Este fato se deve à baixa absorção de umidade da matriz PPS associada ao compromisso estrutural da fibra de carbono durante os ensaios de tração-tração em fadiga. Neste caso, apesar da água assumir a função de um agente tenacificante, modificando algumas das propriedades mecânicas do compósito e melhorando a transferência de tensões dentro e fora do plano do laminado.

As Figuras 5 e 6 apresentam estereofotomicrografias dos laminados PPS-C analisados em alto ciclo (Figura 5) e em baixos ciclos (Figura 6). A partir da Figura 5, pode ser concluído que embora as amostras de PPS-C tenham sido submetidas a 1 milhão de ciclos, não foi possível observar problemas inerentes de delaminações e/ ou trincas. Tanto em regiões próximas aos tabs quanto em regiões centrais das amostras analisas foi observado a existência de uma boa interface entre a matriz e o reforço. Este mesmo comportamento também foi observado em todos os laminados após serem submetidos aos condicionamentos higrotérmicos.

\section{Conclusões}

A partir da análise dos resultados de microscopia óptica realizada nos laminados de PPS-C pode-se concluir que o material fornecido pela empresa TenCate possui uma boa homogeneidade e boa adesão fibra/matriz, não sendo encontrada a presença de descontinuidades do tipo vazios ou delaminações que pudessem comprometer as respostas obtidas a partir dos ensaios mecânicos realizados. Os ensaios de tração constataram que o efeito higrotérmico aumentou a resistência à tração para os laminados PPS-C devido, provavelmente, a incorporação das moléculas de água no compósito diminuir a rigidez da matriz, aumentando, consequentemente, a sua tenacidade. Este comportamento pode ter sido provocado, principalmente, pela expansão do volume da matriz polimérica e pela ocorrência de um maior distanciamento das cadeias moleculares. Desta forma, a água assume a função de um agente tenacificante, modificando algumas das propriedades mecânicas do compósito e melhorando a transferência de tensões dentro e fora do plano do laminado. A partir dos ensaios de fadiga, foi observado que o condicionamento higrotérmico não alterou de forma significativa o comportamento de vida em fadiga dos laminados PPS-C. Nesta avaliação, foram observados pequenos decréscimos de valores da tensão de resistência à ruptura para estes laminados. Este fato se deve à baixa absorção de umidade da matriz PPS associada ao compromisso estrutural destas fibras durante os ensaios de traçãotração em fadiga.

\section{Agradecimentos}

Os autores gostariam de agradecer à FAPESP processo $\mathrm{n}^{\circ}$ 05/54358-7, ao CNPq contrato $\mathrm{n}^{\circ} 134419 / 2005-7$, à TenCate Advanced Composites pelo fornecimento dos laminados, ao CTA por disponibilizar seus laboratórios para a colagem dos tabs utilizados neste trabalho.Os autores também gostariam de agradecer aos técnicos Manoel Francisco dos Santos Filho da UNESP de Guaratinguetá e Francisco de Paiva Reis, da Escola de Engenharia de Lorena-EEL/USP pelo auxílio na realização dos ensaios mecânicos. 


\section{Referências Bibliográficas}

1. Botelho, E. C. \& Rezende, M. C. - Polímeros, 12, p.153 (2002). http:// dx.doi.org/10.1590/S0104-14282002000300007

2. Bersee, H. E. N.; Laan, T. V. D.; Tooren, M. J. L. V. \& Beukers, A. - "Manufacturing of a Thermoplastic Composite Strutural Aircraft Componente" (2005).

3. Costa, G. G.; Botelho, E. C.; Rezende, M. C. \& Costa, M. L. Polímeros, 18, p.81 (2008).

4. Neto, F. L. \& Pardini, L. C. - "Compósitos Estruturais: Ciência e Tecnologia”, Edgar Blücher, São Paulo (2006).

5. Mazur, L. R.; Botelho, E. C.; CostaII, M. L. \& Rezende, M. C. Polímeros, 18,(3), p.237 (2008). http://dx.doi.org/10.1590/S010414282008000300009

6. Jang,J.\& Kim,H.S.-J.Appl.Polym.Sci.,60,p.2297(1996).http://dx.doi. org/10.1002/(SICI)1097-4628(19960620)60:12\%3C2297::AIDAPP29\%3E3.3.CO;2-A

7. Perng, L. H. - Polym. Degrad. Stab., 69, p.323 (2000). http://dx.doi. org/10.1016/S0141-3910(00)00077-X

8. Wiebeck, H. \& Harada J. - "Plásticos de Engenharia - Tecnologia e Aplicação", Artiliber (2005).

9. Mayer, S.; Cândido, G. M. \& Rezende, M. C. - Polímeros, 13, (3), p.147 (2003). http://dx.doi.org/10.1590/S0104-14282003000300004

10. Arici, A.; Sinmazçelik, T. \& Çapan, L. - J. Compos. Mat., 39 (2005).

11. Pastoukhov, A. V. \& Voorwald, J. C. H. - "Introdução à Mecânica da Integridade Estrutural", UNESP (1995).

12. Callister, W. D. - "Material science and engineering", John Wiley \& Sons, New York (1994).

13. Chawla, K. K. - "Composite materials: science and engineering", Springer, New York, p.483 (1998).

14. Bryan, H. - "Fatigue in Composites", Woodhead Publishing Limited, Cambridge, p.742 (2003)

15. Bathias, C. - Int. J. Fatigue, 28, p.1094 (2006). http://dx.doi org/10.1016/j.ijfatigue.2006.02.008

16. Gassan, J. \& Dietz, T. - Compos. Sci. Technol., 61, p.157 (2001). http:// dx.doi.org/10.1016/S0266-3538(00)00205-0
17. Salekeen, S. \& Jones, D. L. - Compos. Struct., 79, p.119 (2007). http:// dx.doi.org/10.1016/j.compstruct.2005.11.040

18. Tay, N. H.; Ma, C. C. M. \& Wu, S. H. - Composites, 26, p.551 (1995).

19. Vinã, J.; Castrillo, M. A.; Argüelles, A. \& Viña, I. - Polym. Compos., 23, (4) (2002). http://dx.doi.org/10.1002/pc.10461

20. Franco L. A. L. - "Fadiga e Análise Fractográfica de Compósitos Termoplásticos sob Condicionamento Ambiental", Tese de Doutorado, Instituto Tecnológico de Aeronáutica, Brasil (2008).

21. Botelho, E. C.; Pardini, L. C. \& Rezende, M. C. - Mater. Sci. Eng., A, p.292 (2007). http://dx.doi.org/10.1016/j.msea.2006.10.127

22. Bismarck, A.; Hofmeier, M. \& Dörner, G. - Compos: part. A, 38, p.407 (2007).

23. Wang, Y. \& Hahn, T. H. - Compos. Sci. Technol., 67, p. 92 (2007). http://dx.doi.org/10.1016/j.compscitech.2006.03.030

24. Yann, R.; Damien, D.; Rachid, E. G. \& Patrick, F. - Mech. Mater., 38, p.1143 (2006). http://dx.doi.org/10.1016/j.mechmat.2006.02.001

25. Zenasni, R.; Bachir, A. S.; Vinã, I.; Argüelles, A. \& Vinã, J. - J. Therm.Compos. Mater., 19, p.385 (2006). http://dx.doi. org/10.1177/0892705706059743

26. Baker, A.; Dutton, S. \& Kelly, D. - "Composite materials for aircraft structures", American Institute of Aeronautics and Astronautics, Blacksburg, p.599 (2004).

27. Botelho, E. C.; Pardini, L. C. \& Rezende, M. C. - Mater. Sci. Eng., A, p.292 (2007). http://dx.doi.org/10.1016/j.msea.2006.10.127

28. Bismarck, A.; Hofmeier, M. \& Dörner, G. - Compos: part. A, 38, p.407 (2007).

29. Cunha, J. A. P.; Costa, L. M. \& Rezende, C. M. - Polímeros, 16, p.193 (2006). http://dx.doi.org/10.1590/S0104-14282006000300008

30. Cândido, G. M. - "Influência do Condicionamento Ambiental na Resistência à Delaminação de Borda Livre em Compósitos Avançados", Tese de Doutorado, Instituto Tecnológico de Aeronáutica - ITA, São José dos Campos (2001).

Enviado: 25/03/11

Reenviado: 10/02/11

Aceito: 10/04/11 